\title{
A Rare Location of Subgaleal Dermoid Cyst: Coronal Suture. A Propos of a Child
}

\section{Mehmet Turgut $\oplus^{\oplus}$, Murat Özcan Yay $\odot$}

\author{
Department of Neurosurgery, Aydın Adnan Menderes University \\ Faculty of Medicine, Aydın, Turkey
}

Cite as: Turgut M, Yay MÖ. A rare location of subgaleal dermoid cyst: Coronal suture. A propos of a child. Trends in Pediatrics 2021;2(3):144-6.

Received: 03 February 2021

Accepted: 05 May 2021

Publication date: 28 September 2021

Keywords: Computed tomography, coronal suture, dermoid cyst, magnetic resonance imaging, surgery

Mehmet Turgut

Department of Neurosurgery, Aydın Adnan Menderes University Faculty of Medicine, Efeler, Aydın, Turkey

ORCID: 0000-0001-7130-2530

drmturgut@yahoo.com
ABSTRACT

Congenital dermoid cyst (CDC) is a benign, uncommon and, slowgrowing lesion covered with normal skin. Its characteristic manifestation is seen at birth and the sole treatment modality is total excision. The coronal suture is a rare location for the CDCS. Herein, we report a 15-month-old female who had cranial subgaleal CDC located in the left coronal suture. The cyst was completely excised after correct radiological diagnosis with computed tomography and magnetic resonance imaging. The differential diagnosis of slow-growing lesions of the cranium and scalp should be considered in the differential diagnosis.

\section{INTRODUCTION}

Congenital dermoid cysts (CDCs) are rare lesions with an incidence of $0.1-0.5 \%$ of all tumors in the cranium. ${ }^{1,2}$ Embryologically, the CDCs consist of the entrapment of ectoderm throughout the fusion lines. ${ }^{3}$ Although CDSs are benign, slow-growing, soft swelling, and non-tender lesions, imaging with computed tomography (CT) and magnetic resonance imaging (MRI) should be performed for the correct diagnosis. The CDCs are usually seen in the midline structure of the brain, however, such lesions can rarely occur at various sites in the skull including coronal suture. There have been very few reports of CDCs arising in the coronal suture. Herein we report a case of completely removed cranial subgaleal CDC which is located in the left coronal suture.

\section{CASE REPORT}

A fifteen-month-old female patient was admitted with a history of swelling lesion in the left frontotemporal region of the scalp since birth. There was no history of fever or seizure and the swelling progressively increased in size. Physical examination demonstrated a firm, non-pulsatile, non-tender and non-compressible swelling overlying the left coronal suture. The remaining systemic and neurological examinations were normal. X-ray of the skull showed a radiolucent area in the left coronal suture (Figure 1A). CT demonstrated a cystic lesion within the left coronal suture without evidence of intracranial extension (Figure 1B). Non-contrast MRI showed an extradural lesion, $10 \times 20 \mathrm{~mm}$ in diameter, with lowintensity on the T1-weighted images and a 

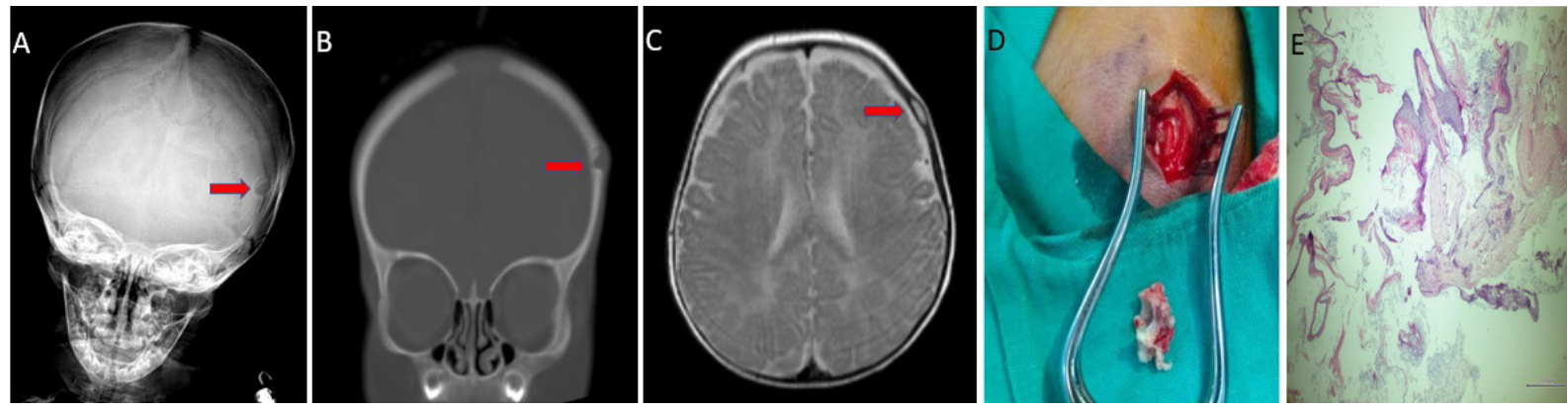

Figure 1. Preoperative X-ray (A), coronal CT bone window of the skull (B), and MRI T2 sequence axial view (C) showing a subgaleal cranial CDC, 10×20 mm in diameter, located in the left coronal suture. Intraoperative appearance of the surgical area and the excised material (D). H.E. × 40; Hematoxylin-Eosin-stained lesion showing keratinized multi-layer flat epithelium that forms the wall of the cystic cavity (E)

high-intensity on the T2-weighted images without apparent connection with the intracranial contents (Figure 1C). A complete excision of the lesion with clear contents was achieved without capsular rupture through scalp incision made over the swelling and the bone structure was carefully curated (Figure 1D). Histopathological examination of the lesion with hematoxylin-eosin staining showed multi-layer flat epithelium that forms the wall of the cystic cavity and the lesion was reported as "CDC" (Figure 1E). The postoperative course was uneventful. The patient was discharged two days after surgery without neurological impairment. Physical and neurological examinations were within normal limits seven months after the surgical intervention.

\section{DISCUSSION}

Anatomically, coronal suture is a rare location for subgaleal CDCs. Herein we report a rare case of completely removed subgaleal CDC which was located in the left coronal suture.

CDCs develop from primordial germ cells 3-5th weeks of embryonic life. ${ }^{4,5}$ As non-pulsatile and fluctuant masses, they arise from the bones of the calvaria, in particular in cranial suture lines, at birth. ${ }^{4-6}$ Histologically, these lesions include a clear fluid and surrounding capsule which is covered with squamous epithelium with various adnexal appendages such as hair follicles, sebaceous, and sweat glands. ${ }^{7,8}$ Typically, they develop from inclusion material and produce a well-defined destruction area in the adjacent bone. ${ }^{9}$ In the largest series to date, Khalid and Ruge described a total of 159 patients with CDCs; of these, only 14 patients (8.8\%) had CDCs along the coronal suture. ${ }^{10}$ Its differential diagnosis involves epidermoid cyst of the cranium, sebaceous cysts, lipomas, subgaleal hematoma, hemangiomas, lymphangioma, and abscess of the scalp..$^{11,12}$

Radiologically, X-ray demonstrates the presence of cranial destruction with well-defined sclerotic margins. ${ }^{4,5}$ The presence of scalloping involving the outer table of the cranium in X-ray examination is a diagnostic finding. However, CT scan and MRI can reveal the details of the lesion with the underlying anatomic structures. ${ }^{13}$

As a rule, the diagnosis of $C D C$ of the skull has to be confirmed by histopathological examination. In our case, the histological analysis revealed the diagnosis of cranial CDC. Total excision of the CDC of the scalp provides both the correct diagnosis and treatment, as did in our case. ${ }^{5}$ Both clinical findings and radiological studies such as $\mathrm{CT}$ or MRI may provide further information for differential diagnosis of these tumors from other congenital lesions of the bony skull and scalp macroscopically. Histopathological diagnosis is always required to confirm the diagnosis of CDC. Despite life-threatening complications in some complicated cases, the overall outcome is usually excellent.

In conclusion, CDC is a lesion located in the midline structures of the cranium. The location of coronal suture is rarely seen. Although imaging with $\mathrm{CT}$ and MRI, complete surgical excision ensures both exact diagnosis and curative treatment. Herein, we 
presented a case of CDS with a very rare location that was treated with successful surgical intervention.

Conflict of Interest: The authors declared no potential conflicts of interest with respect to the research, authorship, and/or publication of this article.

Funding: The authors received no financial support for the research, authorship, and/or publication of this article.

Informed Consent: Parents of the patient provided informed consent to publish the report.

\section{REFERENCES}

1. Pollard ZF, Harley RD, Calhoun J. Dermoid cysts in children. Pediatrics. 1976;57:379-82.

2. Aslan O, Ozveren F, Kotil K, et al. Congenital dermoid cyst of the anterior fontanelle in Turkish children-four case reports. Neurol Med Chir (Tokyo). 2004;44:150-2. https://doi.org/10.2176/nmc.44.150

3. Adachi K, Ishii N, Takahashi H, et al. Congenital dermoid cyst at the anterior fontanelle: Neuroimaging before and after fontanelle closure. J Nippon Med Sch. 2012;79:291-5.

https://doi.org/10.1272/jnms.79.291

4. Makhija D, Sisodiya N, Shah H, et al. Cystic congenital scalp inclusion dermoid: A case report. Dev Period Med. 2016. PMID:28216482.

5. Wong TT, Wann SL, Lee LS. Congenital dermoid cysts of the anterior fontanelle in Chinese children. Childs Nerv
Syst. $1986 ; 2: 175-8$.

https://doi.org/10.1007/BF00706806

6. Bliss M, Grant G, Tittler E, et al. Diagnosis and treatment of pediatric frontotemporal pits: Report of 2 cases. J Neurosurg Pediatr. 2016;18:471-4.

https://doi.org/10.3171/2016.5.PEDS1687

7. Parízek J, Němecek $S$, Německová J, et al. Congenital dermoid cysts over the anterior fontanel. Report on 13 cases in Czechoslovak children. Childs Nerv Syst. 1989;5:234-7.

https://doi.org/10.1007/BF00271025

8. Pannell BW, Hendrick EB, Hoffman HJ, et al. Dermoid cysts of the anterior fontanelle. Neurosurgery. 1982;10:317-23.

https://doi.org/10.1227/00006123-198203000-00004

9. De Carvalho GT, Fagundes-Pereyra WJ, Marques JA, et al. Congenital inclusion cysts of the anterior fontanelle. Surg Neurol. 2001;56:400-5. https://doi.org/10.1016/S0090-3019(01)00621-8

10. Khalid S, Ruge J. Considerations in the management of congenital cranial dermoid cysts. J Neurosurg Pediatr. 2017;20:30-4.

https://doi.org/10.3171/2017.2.PEDS16701

11. Glasauer FE, Levy LF, Auchterlonie WC. Congenital inclusion dermoid cyst of the anterior fontanel. J Neurosurg. 1978;48:274-8. https://doi.org/10.3171/jns.1978.48.2.0274

12. Akhaddar A, Jiddane M, Chakir N, et al. Cerebellar abscesses secondary to occipital dermoid cyst with dermal sinus: case report. Surg Neurol. 2002;58:26670. https://doi.org/10.1016/S0090-3019(02)00847-9

13. Agrawal A, Goel S, Trehan S, et al. Scalloping characteristics in anterior fontanelle dermoid cyst. J Pediatr Neurosci. 2011;6:92-3. https://doi.org/10.4103/1817-1745.84424. 